Asian J. Med. Biol. Res. 2020, 6 (3), 577-586; doi: 10.3329/ajmbr.v6i3.49811

\author{
Asian Journal of \\ Medical and Biological Research \\ ISSN 2411-4472 (Print) 2412-5571 (Online) \\ www.ebupress.com/journal/ajmbr
}

\title{
Article \\ Epidemiological characteristics of child injury in a tertiary paediatric surgical centre in Bangladesh
}

Tanvir Kabir Chowdhury ${ }^{1 *}$, Ayesha Sadia ${ }^{2}$, Rumana Khan ${ }^{2}$, Abida Farjana ${ }^{2}$, Efat Sharmin², Kafil Hasan $^{2}$, Fatima Farhana Rini ${ }^{2}$ and Md. Abdullah Al Farooq ${ }^{3}$

${ }^{1}$ Assistant Professor, Department of Paediatric Surgery, Chittagong Medical College \& Hospital, Chattogram, Bangladesh

${ }^{2}$ Resident doctor, Department of Paediatric Surgery, Chittagong Medical College \&Hospital, Chattogram, Bangladesh

${ }^{3}$ Associate Professor and Head, Department of Paediatric Surgery, Chittagong Medical College \& Hospital, Chattogram, Bangladesh

*Corresponding author: Tanvir Kabir Chowdhury, Department of Paediatric Surgery, Chittagong Medical College \& Hospital, Chattogram 4203, Bangladesh. Tel: +8801771477766; E-mail: ivan_tanvir@yahoo.com

Received: 06 September 2020/Accepted: 28 September 2020/ Published: 30 September 2020

\begin{abstract}
While high income countries (HICs) have reduced the mortality from child injury, it is increasing in the low- and middle-income countries (LMICs). However, injury registry and reporting are inconsistent and not well developed in the LMICs. This study aims at describing the epidemiology of child injury in a tertiary paediatric surgical centre in Bangladesh. We retrospectively analysed all patients of injury between 0 and 12 years of age admitted in the Department of Paediatric Surgery, Chattogram Medical College Hospital during January 2017 to June 2020. Analysis was done for the hospital prevalence, age and sex distribution, seasonal variations, mechanism of injury, site of involvement, and mortality from injury. There were a total of 538 patients and male to female ratio was 2.01:1. Hospital prevalence was $6.71 \%$. Mean age was $6.60 \pm 3.32$ years. School age children were affected more (51.7\%); and "6-10 years" age group had the highest number injuries (251 patients, 46.65\%). The most common mechanisms of injuries were road-traffic accident (RTA, 35.32\%), followed by fall $(26.39 \%)$ and 'stab or cut injury' $(20.63 \%)$. Males experienced more abdominal injuries and females had more perineal injuries $(P=0.00)$. RTA was the commonest mechanism in males $(37.05 \%)$ and falls were the commonest mechanism in females $(32.96 \%)$. 'Stab or cut injury' was the commonest mechanism in infants and toddlers, and RTA was commonest among pre-school and school age children. There were no significant seasonal variations $(P=0.09)$. There were $5.76 \%$ intentional injuries. Mortality was $2.60 \%$ and major causes of mortality were RTA and animal assaults. Injuries were more prevalent during the mid-childhood with an overall increasing trend with age. Mechanism of injury and site of involvement were different among different age groups and between sexes.
\end{abstract}

Keywords: injury; trauma; children; road traffic accident; fall; Bangladesh

\section{Introduction}

Injuries comprise $12 \%$ of global burden of diseases and childhood injury is a major public health problem which is emerging as an epidemic (WHO, 2008; Kundal et al., 2017; Kunwar et al., 2020). Injuries kill more children globally than HIV, tuberculosis and malaria combined (Global initiative for children's surgery, 2020). Every year, injury is responsible for hospitalization of tens of millions of children and about one million child mortality in the world (WHO, 2008). It has been estimated that more than 95\% of all injury deaths in children occur in low- and middle-income countries (LMICs) (Kunwar et al., 2020). While childhood injury mortality reduced by up to 50\% in high-income countries (HICs) between 1970 and 1995, injury management system in many LMICs are still at their infancy and many are not able to report and analyse child injury data appropriately 
(Babu et al., 2015). The South and East Asian community surveys of injury reported that injury was responsible for 30\% of deaths in 1-3-year-olds, 40\% in 4-year- olds and 50-60\% among those aged 5 to 17 years (Linnan et al., 2007). Consistent with the concept of child-injury pyramid, study conducted by UNICEF and the Alliance for Safe Children showed that, for each death there are 12 children admitted to hospital or permanently disabled and 34 children who needed medical care or missed school or work because of an injury (Linnan et al., 2007). Studies that described the epidemiology, prevalence, mode of injury, site of injury and outcome of paediatric trauma or injury in different countries have produced diverse results from region to region; and the characteristics varied greatly by age, gender, race and socioeconomic status. It means that prevention and management strategies should be different among countries.

Children (up to 18 years) comprise $49.5 \%$ of total population of Bangladesh (Banu et al., 2013). Bangladesh health and injury survey among 171,366 households, conducted in 2003, documented an overall child injury rate of 1,592 per 100,000 children per year; which means that about $2 \%$ children were injured significantly enough to require medical care, or lost at least three days of school or work in a year. More than 30,000 children were fatally injured in the year before the survey which is about 83 children per day, or three children per hour (Bangladesh health nad injury survey Report on children, 2004). Although the pattern of childhood mortality and morbidity is changing from infectious disease to non-communicable diseases and injuries, most of the child health programs are still focused on infectious and nutritional causes of child death (Chowdhury et al., 2009). There have been some population-based studies on child injuries, which were mainly based on surveys or questionnaires; but hospital-based objective injury reporting is still scarce (Mashreky, 2012; Chowdhury et al., 2008; Haque et al., 2019). The aim of this study was to find out the hospital prevalence, mechanism and site of injury, seasonal differences, age and sex distribution of child injury and their relation with one other in a paediatric surgical centre of a tertiary government academic hospital in Bangladesh.

\section{Materials and Methods}

\subsection{Study Design and Setting}

This was a retrospective study carried out in the Department of Paediatric Surgery, Chattogram Medical College Hospital $(\mathrm{CMCH})$, which is a tertiary academic hospital in Bangladesh. Chattogram (former Chittagong) is situated at the south-east part of the country and is the second largest city in the country. $\mathrm{CMCH}$ is the largest referral centre for paediatric surgical services for about one fifth of the population of the country (161.4 million). Children aged 12 years or less are admitted in our department. All children of this age range who were admitted with a diagnosis of any kind of injury between January 2017 and June 2020 (3.5 years) were included in this study. Patients with minor injury who were treated in the outpatient or emergency department but were not admitted in the in-patient department were excluded from the study. Patients with obvious head injuries, fractures, burns, and ophthalmic injuries are treated in the Neurosurgery, Orthopaedic surgery, Burn and Plastic Surgery and Ophthalmology departments, respectively. Thus, patients who were directly admitted in those wards were not included in the study. However, patients with above mention injuries who initially got admitted in our ward and were treated or subsequently referred to other wards, were included in the study. Patients with drowning or poisoning, and snake bite are admitted in the Paediatrics and dedicated snake bite ward, respectively and were not included (Dhaka Tribune, 2020). Foreign body ingestion by children was not also included (Chowdhury et al., 2020). The general objective of the study was to gather epidemiological data on child injury in our institute; and the specific objectives were to find out the hospital prevalence, age and sex distribution, seasonal variations, mechanism of injury, site of involvement, and mortality from injury. Due to inconsistencies in the records, the time of the day when injury occurred and the circumstances of the injury could not be retrieved for all patients and were not analysed.

\subsection{Data collection and analysis}

Hospital records of all patients with injury during the study period were retrieved into a predesigned proforma with emphasis on epidemiology. Age, sex, date of admission, mechanism of injury, site of injury (isolated or polytrauma), and mortality were recorded. A total of 565 patients with injury were admitted during the study period; however, in 25 patients, either the mechanism of injury or the site of injury was not documented and they were excluded from the study. There were also 2 patients with old wound in the fingers following electrocution, and they were also excluded. Thus, a total of 538 patients were included for final analysis. Prevalence was calculated from total monthly admissions of all patients retrieved from the patient registry. Two types of age group specific stratifications were done to compare our findings with other studies. Firstly, children were classified into infants (up to 1 year), toddlers (1-3 years), preschool (3-6 years) and school-age children (612 years) (Paul et al., 2018). Secondly, children were classified as less than 5 years (early childhood), 5-10 
years (mid childhood), and more than 10 years of age (late childhood). Date of admission was coded separately with name of month, and name of seasons. Seasonal variation was analysed according to both the Northern Meteorological Seasons and Bangladeshi seasons. Northern Meteorological Seasons are Winter (December to February), Spring (March to May), Summer (June to August) and Fall (September to November) (Bikos and Kher, 2020). There are six seasons in Bangladesh and these are Winter (mid-December to mid-February), Spring (mid-February to mid-April), Summer (mid-April to mid-June), Rainy Season (mid-June to mid-August), Autumn (mid-August to mid-October), and Late Autumn (mid-October to mid-December) (Banglapedia, 2014). Since the year 2020 is not complete yet and it is also influenced by COVID-19 pandemic, seasonal variations were calculated between 2017 and 2019 only, among a total of 474 patients.

Compiled data were coded in unique alphanumeric codes for each variable and subjected to statistical analysis using both Microsoft Excel 2019 and SPSS version 22; and cross checked to correct errors. Categorical variables were described as frequency and percentage and compared using Chi-square test. Continuous variables were expressed as mean or median \pm standard deviation and comparison was done by independent sample $t$ test. $P$ value $<0.05$ was considered to be significant. Confidentiality was maintained using unique identifiers and by password protected data entry software with restricted users.

\section{Results}

Among a total of 538 injury patients, 359 were male and 179 were female (ratio 2.01: 1). Child injury was $6.71 \%$ of all admissions ( 8017 patients, male: female $=2.01: 1$ ). Age ranged from 0 day to 12 years (mean $6.60 \pm$ 3.32 ; median 7). Male patients were elder than female patients (mean $6.94 \pm 3.47$ vs $5.93 \pm 2.90 ; P=0.00$ ). School age children suffered from injury more (51.7\%); and "6-10 years" age group had the highest number of patients (251 patients, 46.65\%). With 61 patients $(11.34 \%)$, the 6th year of life represented the year of highest occurrence (Figure 1). Male to female ratio was $1.73: 1$ and 1.67:1 in "0-5 years" and "6-10 years" age groups, respectively. However, male to female ratio was exceedingly high in ">10 years" age group (6.33:1). This ratio was $2.00,1.58,1.48$, and 2.61 among infants, toddlers, preschool and school aged children, respectively $(\mathrm{P}=0.03)$.

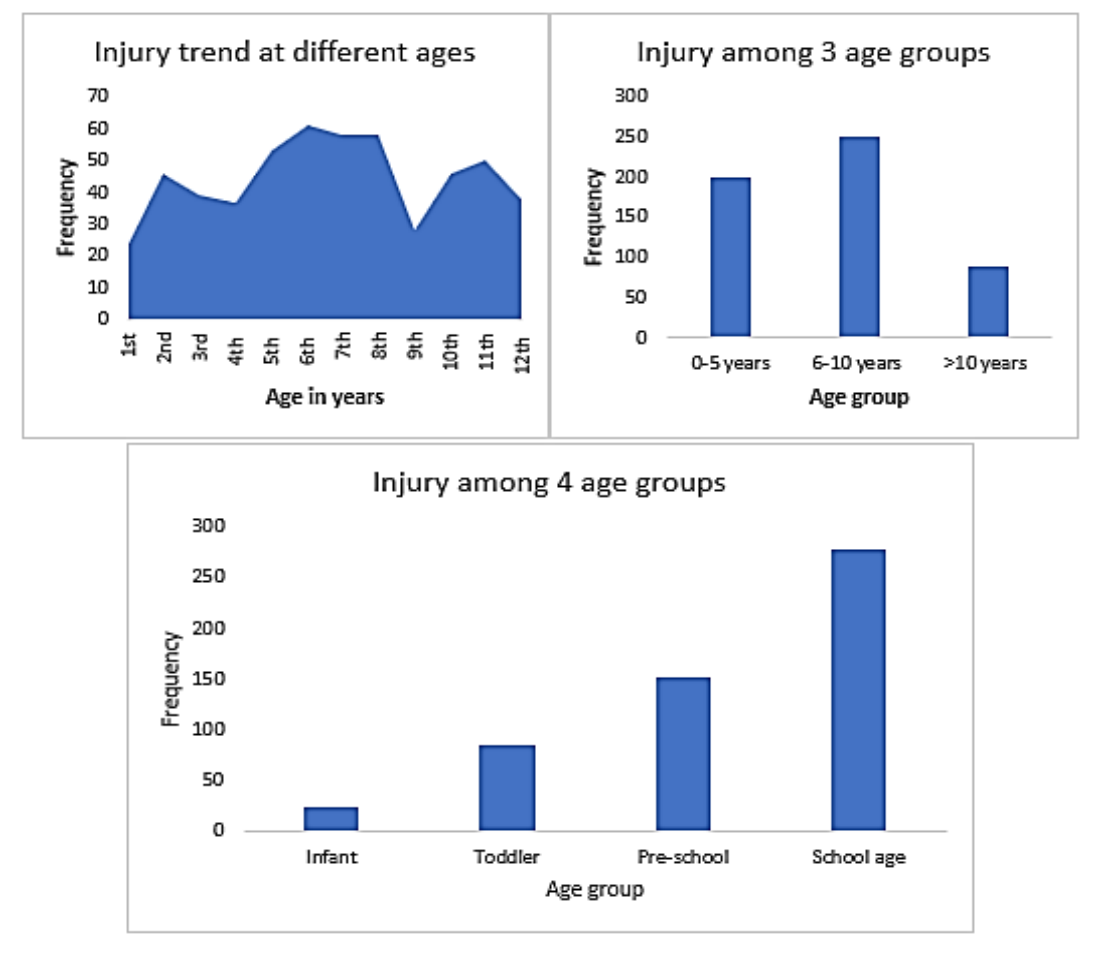

Figure 1. Frequency of injury at different ages and age groups.

Road-traffic accident (RTA) was the most common mechanism of injury (35.32\%), followed by fall (26.39\%) and 'stab or cut injury' (20.63\%) (Table 1). Among the patients who had falls, 76 (53.52\%) had high fall and 66 (46.48\%) had low fall. Abdomen was the most common site of injury (196 patients), followed by perineum (112 patients) and limbs (69 patients). The most common mechanisms of abdominal injuries were also RTA (42.86\%), fall $(26.53 \%)$ and 'stab or cut injury' $(18.37 \%)$. On the other hand, fall $(35.71 \%)$ was the most common mechanism of perineal injury, followed by RTA (30.36\%). Major causes of chest injuries were RTA 
and 'stab or cut' ( $11 \%$ by both mechanisms). RTA was also the most common mechanism for limb injuries and injuries involving multiple sites. Among the other sites, 'struck or hit by person or object' was the commonest cause of back injury ( 7 patients), and tongue bite and fall were the most common causes of 'face or oral cavity injury' (10 patients by each mechanism). There were 31 (5.76) intentional injuries and 507 (94.24\%) unintentional injuries. Among patients of 'hit by person', there were 5 cases of sexual assault and 26 cases of physical assault.

Table 1. Relation of site of injury with mechanism of injury.

\begin{tabular}{|c|c|c|c|c|c|c|c|c|c|c|c|c|c|c|}
\hline Mechanism & 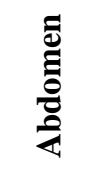 & $b^{\circ}$ & 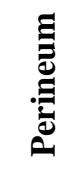 & se & 参 & de & & $s$ & $\frac{\vec{g}}{\tilde{U}}$ & $x^{\circ}$ & 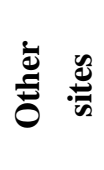 & $s^{\circ}$ & बूँ & se \\
\hline RTA & 84 & 42.86 & 34 & 30.36 & 24 & 34.78 & 30 & 50.00 & 11 & 32.35 & 7 & 10.45 & 190 & 35.32 \\
\hline Fall & 52 & 26.53 & 40 & 35.71 & 17 & 24.64 & 8 & 13.33 & 8 & 23.53 & 17 & 25.37 & 142 & 26.39 \\
\hline Stab or cut & 36 & 18.37 & 18 & 16.07 & 17 & 24.64 & 12 & 20.00 & 11 & 32.35 & 17 & 25.37 & 111 & 20.63 \\
\hline Struck or hit & 12 & 6.12 & 8 & 7.14 & 4 & 5.80 & 7 & 11.67 & 4 & 11.76 & 13 & 19.40 & 48 & 8.92 \\
\hline Insect bite & 3 & 1.53 & 7 & 6.25 & 4 & 5.80 & 1 & 1.67 & 0 & 0.00 & 0 & 0.00 & 15 & 2.79 \\
\hline Animal bite & 5 & 2.55 & 3 & 2.68 & 3 & 4.35 & 2 & 3.33 & 0 & 0.00 & 1 & 1.49 & 14 & 2.60 \\
\hline Tongue bite & 0 & 0.00 & 0 & 0.00 & 0 & 0.00 & 0 & 0.00 & 0 & 0.00 & 10 & 14.93 & 10 & 1.86 \\
\hline Birth injury & 0 & 0.00 & 2 & 1.79 & 0 & 0.00 & 0 & 0.00 & 0 & 0.00 & 2 & 2.99 & 4 & 0.74 \\
\hline Gunshot or blast & 4 & 2.04 & 0 & 0.00 & 0 & 0.00 & 0 & 0.00 & 0 & 0.00 & 0 & 0.00 & 4 & 0.74 \\
\hline Total & 196 & 100 & 112 & 100 & 69 & 100 & 60 & 100 & 34 & 100 & 67 & 100 & 538 & 100 \\
\hline
\end{tabular}

RTA was the most common mechanism of injury in males (133 patients, 37.05\%). On the other hand, fall was the most common mechanism in females (59 patients, 32.96\%). However, males suffered more with high level falls than females (47 vs 29); and both had same number of same level falls (33 in each sex). Leech bite was more common in females ( 10 vs 1 ), as was tongue bite (7 vs 3 ). Figure 2 depicts the sex distribution of mechanism of injury. Abdominal injury (42.06\%) occurred significantly more commonly in males while perineal injury $(28.49 \%)$ occurred significantly more in females $(\mathrm{P}=0.00)$. Although fewer in number, the proportion of injuries to lower limbs, "face or oral cavity" and chest were relatively more in females than males (Table 2).

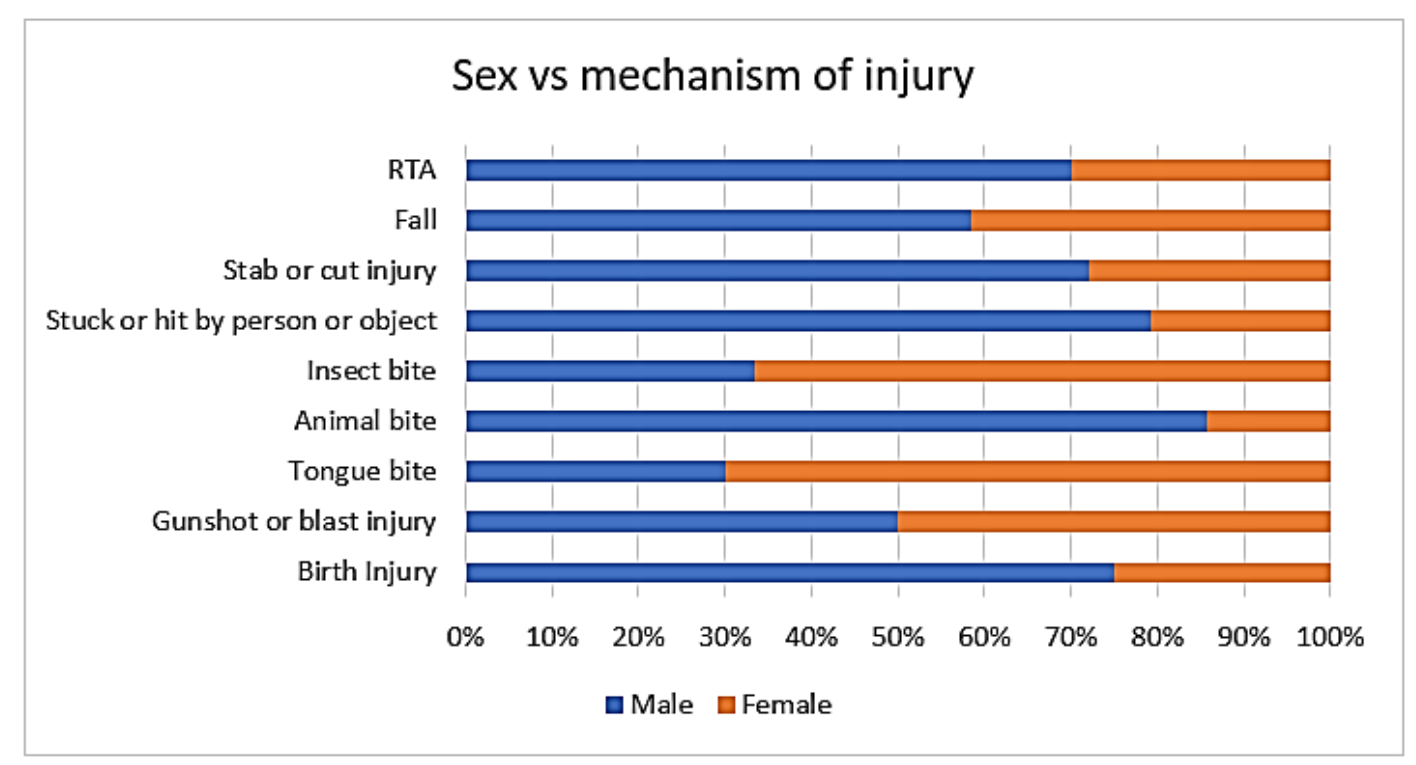

Figure 2. Differences in mechanism of injury between sexes. 
Table 2. Differences in site of injuries between sexes.

\begin{tabular}{lllllll}
\hline Site of injury & Male & \% & Female & \% & Total & \% \\
\hline Abdomen & 151 & $42.06 \%$ & 45 & $25.14 \%$ & $\mathbf{1 9 6}$ & $\mathbf{3 6 . 4 3 \%}$ \\
Perineum & 61 & $16.99 \%$ & 51 & $28.49 \%$ & $\mathbf{1 1 2}$ & $\mathbf{2 0 . 8 2 \%}$ \\
Multiple & 40 & $11.14 \%$ & 20 & $11.17 \%$ & $\mathbf{6 0}$ & $\mathbf{1 1 . 1 5 \%}$ \\
Lower limb & 31 & $8.64 \%$ & 19 & $10.61 \%$ & $\mathbf{5 0}$ & $\mathbf{9 . 2 9 \%}$ \\
Face or oral cavity & 19 & $5.29 \%$ & 17 & $9.50 \%$ & $\mathbf{3 6}$ & $\mathbf{6 . 6 9 \%}$ \\
Chest & 21 & $5.85 \%$ & 13 & $7.26 \%$ & $\mathbf{3 4}$ & $\mathbf{6 . 3 2 \%}$ \\
Upper limb & 13 & $3.62 \%$ & 6 & $3.35 \%$ & $\mathbf{1 9}$ & $\mathbf{3 . 5 3 \%}$ \\
Back & 12 & $3.34 \%$ & 4 & $2.23 \%$ & $\mathbf{1 6}$ & $\mathbf{2 . 9 7 \%}$ \\
Head or neck & 11 & $3.06 \%$ & 4 & $2.23 \%$ & $\mathbf{1 5}$ & $\mathbf{2 . 7 9 \%}$ \\
\hline Total & $\mathbf{3 5 9}$ & $\mathbf{1 0 0 . 0 0 \%}$ & $\mathbf{1 7 9}$ & $\mathbf{1 0 0 . 0 0 \%}$ & $\mathbf{5 3 8}$ & $\mathbf{1 0 0 . 0 0 \%}$ \\
\hline
\end{tabular}

'Stab or cut injury' (6/24) was the most common mechanism of injury among infants, followed by falls (4/24) (Figure 3). Toddlers also suffered more from 'stab or cut injury' (29/85), followed by RTAs (25/85). Among both preschool and school age children, RTA was the commonest mechanism of injury (72/151 and 90/278, respectively), followed by falls (38/151 and 83/278, respectively). However, RTA was the commonest mechanism of injury among all the '0-5 years', 6-10 years' and ' $>10$ years' age groups $(72 / 199,94 / 251$, and $24 / 88$, respectively). Nevertheless, 'stab or cut injury' was the second most common mechanism of injury among ' $0-5$ years' old (49/199). Fall was the second most common mechanism of injury in both ' $6-10$ years' and ' $>10$ years' age groups ( $78 / 251$ and $23 / 88$, respectively).

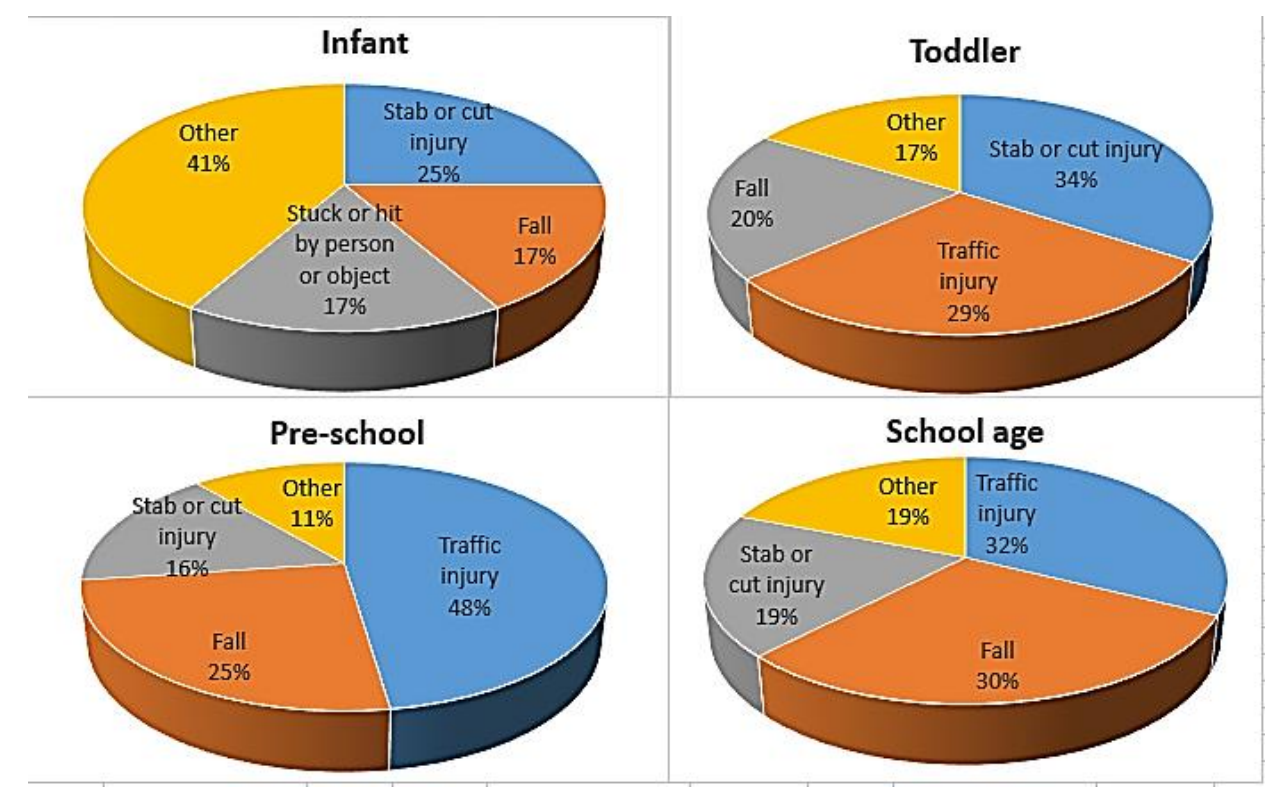

Figure 3. Mechanism of injury among different age groups. (infants, $n=24$; toddler, $n=85$; pre-school, $n=151$; school age, $n=278$ ).

Both the numbers of injured patients and their relative percentage among total admitted patients were more during the summer of the northern meteorological seasons. However, this was not statistically significant $(\mathrm{P}=0.09)$. On the other hand, among the Bangladeshi seasons, there were more patients during rainy season and during the months of July and August (Figure 4). However, this was not also significant ( $\mathrm{P}=0.06)$. 


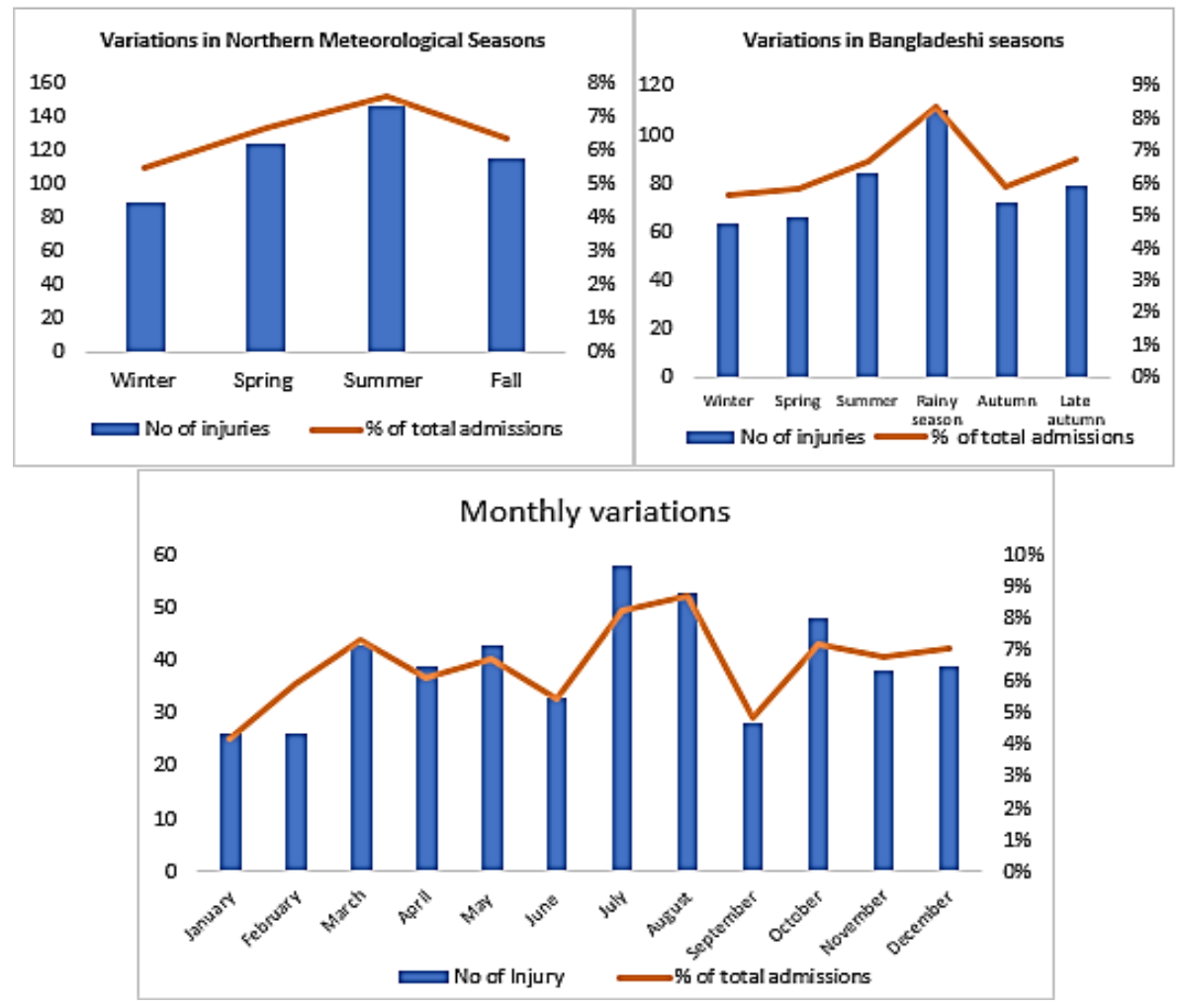

Figure 4. Seasonal variations of injury occurrences (analysis between 2017 and 2019, $n=474$ ).

Fourteen patients died from injury during the study period, which was $2.60 \%$ of all admitted injury patients and $3.59 \%$ of mortalities from all diseases (390 patients). The overall mortality from all causes in this department was $4.86 \%$ of admitted patients (390 mortalities from 8017 admissions). Among the mortalities, 12 were male and 2 were female. Hospital stay ranged from 0-12 days (mean 2.36\%) for the patients who died in hospital. Among them, 10 patients (71.43\%) died within 24 hours of admission. Median age of mortality was 9 years and all patients, except one infant, were more than 5 years old. RTA and animal assault were the most common mechanisms of injury leading to death (Figure 5). Abdominal injury was the most common site (8), followed by polytrauma (5) and limb (1).

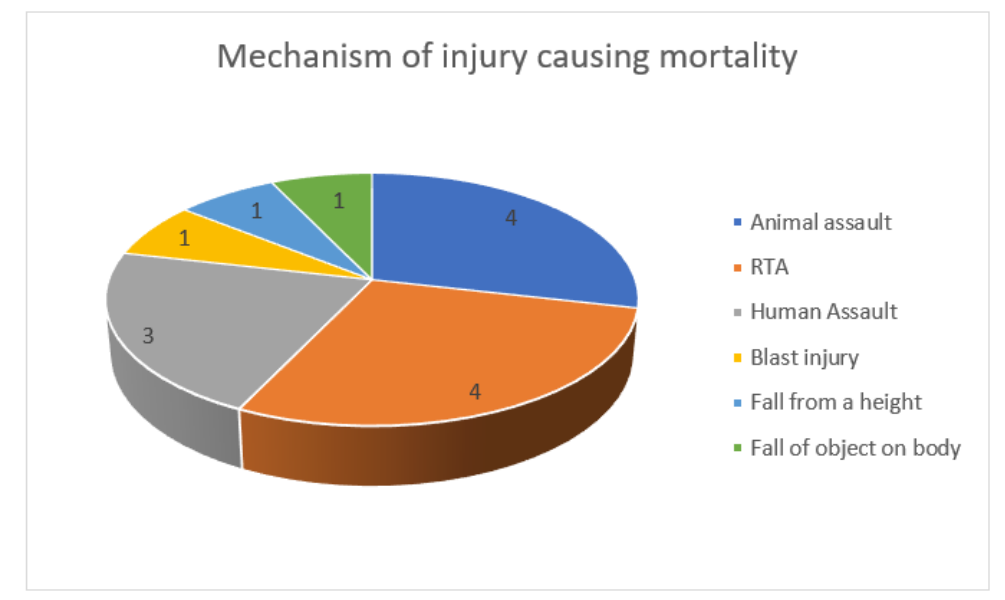

Figure 5. Mechanism of injury in patients who died from their injuries.

\section{Discussion}

Due to their high curiosity, less knowledge about surrounding dangers, and anatomical variations from adult; children usually experience at least one event of injury in their childhood (Paul et al., 2018). The amount of injuries which need hospital care are also not negligible. There are also injuries which cause life-long disabilities and deaths. This study offers a comprehensive description of childhood injuries in a paediatric 
surgical centre and shows that the mechanism and site of injuries vary among ages and between sexes. The prevalence of child injury in this department was $6.71 \%$. Studies from various parts of India, our neighbouring country, showed prevalent rates from 5.5\% to 19.2\% (Paul et al., 2018). The trauma patterns and sites also varied greatly among studies. These differences are probably due to the nature and level of the hospitals; types of service deliveries by different departments such as, emergency, orthopaedic, and neurosurgical departments; different cut of ages such as $<12,<15,<18$ and $<20$ years; and the referral patterns. We used a cut of age of 12 years and our department provides general paediatric surgical services including paediatric casualty, neonatal surgery, and paediatric urology. That is why, head injury and limb fractures, two common injuries among some studies, were underrepresented in our study; and burns, drowning and snake bites were not represented at all. An earlier survey from our institute reported that injury among 0-15 years old represented $11.67 \%$ of all injury admissions in the adult Casualty, Orthopaedics, Neurology, Medicine, Psychiatry, and Burn and plastic surgery departments (Nourin et al., 2019). Which means that the interpretation of the results from this study will be different from community-based studies and studies from other departments.

Almost all studies described a male preponderance to injury and this study was not different. However, this sex difference was not significantly more than the sex ratio for all admissions in our department. The reasons behind a higher male preponderance were suggested to be more outdoor physical activities and riding of vehicles by boys. Boys also have higher activity level, become involved in more risk-taking activities, and behave more impulsively. Their socialization is different from girls and they are more likely to be allowed to roam further and play alone (WHO, 2008). The commonest cause of injury and the commonest site involved were different between males and females in this study which showed that males were more victims of RTAs and abdominal injuries, while females experienced more falls and perineal injuries. This sex difference for mechanism of injury was consistent with study from Kundal et al.; however in their study, polytrauma was the commonest followed by abdominal injuries (Kundal et al., 2017).

RTA was the most common mechanism of injury in this study, followed by falls and 'stab or cut injury'. A community based survey in Bangladesh showed that falls were the commonest mechanism of injury in children less than 18 years, followed by burns and 'injury by sharp cutting object or cut injury' (Chowdhury et al., 2009). Their study also found that child pedestrians were the main victims of RTAs (Chowdhury et al., 2009). We also observed a much higher trends of 'pedestrian hit by vehicles' in our study during data collection, however, due to incomplete recording of the exact nature of injury in many patients, we could not analyse this in details. An international study on epidemiology of paediatric trauma reported RTA, fall and interpersonal violence to be the commonest mechanisms of injuries; however they found that RTAs and falls were significantly more in LMICS and HICs, respectively (Bradshaw et al., 2018). Data from 103 German trauma centres also revealed that most common causes of injury in children were traffic related accidents, followed by falls (Buschmann et al., 2008). Study from 1511 Australian children also showed that motor vehicle collisions were the commonest cause of injury, followed by 'struck by/ collisions with an object or person' (Beck et al., 2018). On the other hand, a study from Varanasi, in one of the largest trauma centres in India, reported falls to be the commonest cause of injury among children (Kunwar et al., 2020). Another study from a tertiary centre in Madhya Pradesh, India also reported that falls were the most common mechanism among 791children (Sharma et al., 2011). A study in Nigeria surveyed among caregivers in 3 hospitals and found that kerosene poisoning was the commonest domestic mechanism of injury followed by falls (Abubakar et al., 2018). Falls were also reported to be the most common cause of injury in various studies from Uganda, Saudi Arabia and India (Babu et al., 2015). The community based survey in Bangladesh showed that fall was the 4th leading cause of morbidity after infancy among children (Chowdhury et al., 2009). Evidence from Canada suggested that implementation of effective prevention strategies can reduce $20 \%$ falls among less than 10- years-old children and can create a net savings of over US\$ 120 million each year (WHO, 2008). Studies have suggested that safe play areas and furniture, safe construction and improved supervision are important factors in reducing fall related injuries (Babu et al., 2015). WHO suggested that prevention strategies should include education, training, research, creation of safer environments, and establishment of effective policies to reduce risk (WHO, 2018b). Animal bite is also an important cause of injury worldwide and dog bites causes tens of millions of injuries annually accounting for 76-94\% of all animal bites. Children comprise the largest percentage and mid to late childhood is the most vulnerable period (WHO, 2018a). Monkey bite is also not very uncommon in Indian subcontinent. In our study animals involved in child injury were dog, bull, monkey and elephant. Although snake bite was not included in this study, earlier report from Bangladesh showed that $33 \%$ of snake bites occurred among children and young adults less than 20 years old (Rahman et al., 2010).

Abdominal injury occurred most commonly in our children. However, we excluded patients who were admitted directly in the neurosurgery and orthopaedic departments. Data from the German and the Australian cohort 
showed that head injuries were most common among children (Buschmann et al., 2008; Beck et al., 2018). Data from the 'Trauma Audit and Research Network' in UK showed that limb injuries were commonest among 24,218 paediatric trauma cases (Bayreuther et al., 2009). Musculoskeletal injuries were also the commonest in the report from Varanasi and Madhya Pradesh (Sharma et al., 2011; Kunwar et al., 2020). Buschmann et al. found that limb injuries in children increased with age which might be due to the bony structure in children with thick periosteum and elastic matrix that requires a higher impact to cause fractures, a better ratio of soft parts to bone, and a smaller limb surface in relation to the body surface (Buschmann et al., 2008). The activity and mobility of the child also increases with age. Similarly, the elasticity of the immature chest due to more cartilage content and incomplete ossification of the ribs are also protective against severe thoracic injuries in children (Buschmann et al., 2008). It has also been suggested that the incidence of life threatening multiple injuries is not common in children, however, these were a major cause of mortality in children older than 1 year in Germany (Buschmann et al., 2008).

The mean age of 6.6 years in this study is similar to data from other South East Asian countries (Paul et al., 2018). In the international study, the mean age was 7 years (Bradshaw et al., 2018). The percentage of injuries among different age groups were also nearly similar to most of the studies (Paul et al., 2018). Consistent with the WHO report on child injury, the number of injuries and the gender gap for injuries increased with age (WHO, 2008). 'Stab or cut injury' was the commonest mechanism of injury in infants and toddlers in our study, while a study from emergency department of a tertiary hospital in South India reported falls to be commonest among them (Paul et al., 2018). Data from Japanese trauma registry showed that falls were the commonest mechanism in infants and toddlers, and RTAs were commonest among older children (Aoki et al., 2019). A study from a level-1 trauma centre in New Delhi, India, reported that falls had an incremental upward trend with age, while the South Indian study showed a decreasing trend (Babu et al., 2015; Paul et al., 2018). Seasonal variation of different types of injuries in this study was not significant. However, more injuries were found in the months of July and August, which was described as Summer in the Northern Meteorological Seasons and Rainy Season in Bangladeshi Seasons. Earlier, a study from adult trauma cases in the USA described significant seasonal variations of mechanism of injury and reported that falls were significantly more during winter and RTAs were more during fall and winter than spring (Nahmias et al., 2017). The South Indian study reported that majority of injuries in children occurred during the most active part of the day ( 6 am- $5 \mathrm{pm})$ and about half of their patients presented during the afternoon shift (3 pm-10 pm) (Paul et al., 2018). Another study from a rural background of Central India reported that most of the paediatric trauma occurred between 12 noon to 4 pm which corresponded to the school leaving time when the children were in a hurry to go back home (Sharma et al., 2016). However, we could not analyse these because of lack of proper recording of time of injury. We also could not analyse the place of injury such as, school, home, roads, play ground or other places.

The mortality rate in our injury patients was $2.60 \%$; RTA and animal assaults being the major causes of death. This is better than many other reports (Kundal et al., 2017; Aoki et al., 2019). Most deaths occurred in more than 5 years old children, while many other studies reported more mortalities among younger age groups (Sharma et al., 2011). According to WHO, RTAs alone are the leading cause death among 5-19-year olds and the second leading cause of death among 5-14-year-olds (WHO, 2008). Every year, 1.35 million people die from road traffic crashes in the world and 20-50 million people suffer non-fatal injuries. WHO recognizes the third Sunday of November as 'the World Day of Remembrance for Road Traffic Victims'. Falls are also an important cause of death worldwide, being the 12th leading cause of death among 5-9- and 15-19-years old children. More than $80 \%$ of falls among all ages occur in LMICs, with the Western Pacific and the South East Asian regions accounting for about $60 \%$ of these deaths (WHO, 2008). Globally RTAs, drowning, burns, falls and poisoning comprise $60 \%$ of all child injury deaths (WHO, 2008). However, HICS have reduced the child mortality from injury by implementing advanced trauma evaluation and care (Buschmann et al., 2008; Bayreuther et al., 2009; Bradshaw et al., 2018; Aoki et al., 2019). On the other hand, mortality from child injury in the LMICs is increasing (Chowdhury et al., 2009). The LMICs should increase their effort in combatting the childhood injury morbidity and mortality.

This study has several limitations. Since this was a hospital-based study, it could not find the actual prevalence of trauma in children. It is known that in the LMICs, a large number of injury victims do not attend hospital for treatment (Chowdhury et al., 2009). Moreover, it was a tertiary centre where majority of the patients are referred from local centres. So, the community pattern of trauma might be different from our finding. We also could not describe the children who were admitted directly into other departments. This was also a retrospective study and we could not analyse many related factors due to incomplete data recording. In spite of these limitations, this study identified specific groups of children who are at greater risk of experiencing certain types of injuries. It also described the trauma pattern in one of the largest paediatric surgical referral centres in a 
LMIC and envisaged the need for proper trauma registry and reporting in these countries for proper planning for the prevention and treatment of child injuries.

\section{Conclusions}

This study gives an idea about the epidemiology of child injury in this region. The hospital prevalence was $6.71 \%$. School aged children, especially the 6-10 years old, had more injuries. RTA was the commonest mechanism of injury in males and falls occurred more in females. Abdominal injury occurred more in males and females suffered more from perineal injuries. Seasonal variations did not have a major impact on the number or mechanism of injury. Mortality was $2.60 \%$ and RTA and animal assaults were major causes of mortality.

\section{Conflict of interest}

None to declare.

\section{References}

Abubakar S, A Ahmed, Z Farouk, M Gadanya and ML Jimoh, 2018. Prevalence and pattern of unintentional domestic accidents and trauma amongst children attending public hospitals in Kano, Nigeria. Sahel Med. J., 21: 6-12.

Aoki M, T Abe, D Saitoh and K Oshima, 2019. Epidemiology, Patterns of treatment, and Mortality of Pediatric Trauma Patients in Japan. Sci. Rep., 9: 917.

Babu A, A Rattan, P Ranjan, M Singhal, A Gupta, S Kumar, B Mishra and S Sagar, 2015. Are falls more common than road traffic accidents in pediatric trauma? Experience from a Level 1 trauma centre in New Delhi, India. Chin. J. Traumatol., 19: 75-78.

Bangladesh health and injury survey Report on children, 2004. Available at: https://www.sharenetbangladesh.org/bangladesh-health-injury-survey-report-children/, Accessed: 13 September 2020.

Banglapedia, 2014. Season - Banglapedia: National Encyclopedia of Bangladesh. Available at: http://en.banglapedia.org/index.php?title=Season, Accessed: 10 September 2020.

Banu T, TK Chowdhury, M Kabir, R Talukder and K Lakhoo, 2013. Bringing surgery to rural children: Chittagong, Bangladesh experience. World J. Surg., 37: 730-736.

Bayreuther J, S Wagener, M Woodford, A Edwards, F Lecky, O Bouamra and E Dykes, 2009. Paediatric trauma: injury pattern and mortality in the UK. Arch. Dis. Child. Educ. Pract. Ed., 94: 37-41.

Beck B, W Teague, P Cameron and BJ Gabbe, 2018. Causes and characteristics of injury in paediatric major trauma and trends over time. Arch. Dis. Child., 104: 256-261.

Bikos K and A Kher, 2020. Seasons: Meteorological and Astronomical. Available at: https://www.timeanddate.com/calendar/aboutseasons.html, Accessed: 10 September 2020.

Bradshaw CJ, AS Bandi, Z Muktar, MA Hasan, TK Chowdhury, T Banu, M Hailemariam, F Ngu, D Croaker, R Bankolé, T Sholadoye, O Olaomi, E Ameh, AD Cesare, E Leva, Y Ringo, L Abdur-Rahman, R Salama, E Elhalaby, H Perera, C Parsons, S Cleeve, A Numanoglu, SV As, S Sharma and K Lakhoo, 2018. International study of the epidemiology of paediatric trauma: PAPSA research study. World J. Surgery, 42: $1885-1894$.

Buschmann C, CA Kühne, C Lösch, D Nast-Kolb and S Ruchholtz, 2008. Major trauma with multiple injuries in german children: a retrospective review. J. Pediatr. Orthop., 28: 1-5.

Chowdhury SM, A Rahman, SR Mashreky, S Giashuddin, L Svanström, LG Hörte, M Linnan, S Shafinaz, IJ Uhaa, and AKMF Rahman, 2008. Childhood fall: epidemiologic findings from a population-based survey in Bangladesh. Int. J. Disabil. Hum. Dev., 7: 81-87.

Chowdhury SM, A Rahman, S R Mashreky, S M Giashuddin, L Svanström, L G Hörte and F Rahman, 2009. The horizon of unintentional injuries among children in low-income setting: an overview from Bangladesh health and injury survey. J. Environ. Public Health, 2009:435403.

Chowdhury TK, D Sadab, MM Sajid and MAA Farooq, 2020. Foreign body ingestion by children: an analysis of age and types at a tertiary hospital in Bangladesh. Asian J. Med. Biol. Res., 6: 299-304.

Dhaka Tribune, 2020. Bangladesh to produce snake antivenom locally. Dhaka. Available at: https://www.dhakatribune.com/bangladesh/nation/2020/01/20/bangladesh-to-produce-snake-antivenomlocally, Accessed: 17 September 2020.

Global initiative for children's surgery, 2020. Available at: https://www.globalchildrenssurgery.org/, Accessed: 14 September 2020. 
Haque MA, S Janson, S Moniruzzaman, AKMF Rahman, SS Islam, SR Mashreky and UB Eriksson 2019. Children's exposure to physical abuse from a child perspective: A population-based study in rural Bangladesh. PLoS ONE, 14: e0212428.

Kundal VK, PR Debnath and A Sen, 2017. Epidemiology of pediatric trauma and its pattern in urban India: a tertiary care hospital-based experience. J. Indian Assoc. Pediatr. Surg., 22: 33-37.

Kunwar A, B Manjhi, A Saurabh and S Shekhar, 2020. Epidemiology and pattern of paediatric trauma in one of the biggest trauma centres of India. Int. J. Res. Orthop., 6: 1-5.

Linnan M, LV Anh, PV Cuong, F Rahman, A Rahman, S Shafinaz, C Sitti-Amorn, O Chaipayom, V Udomprasertgul, MC Lim-Quizon, G Zeng, J Rui-wei, Z Liping, K Irvine and T Dunn, 2007. Child mortality and injury in Asia: survey results and evidence. Florence. Available at: https://www.unicefirc.org/publications/pdf/iwp_2007_06.pdf.

Mashreky SR, 2012. Child injury: An emerging health burden in low-income countries. South East Asia Journal of Public Health, 2: 1-2.

Nahmias J, S Poola, A Doben, J Garb and RI Gross, 2017. Seasonal variation of trauma in western massachusetts: fact or folklore? Trauma Surg Acute Care Open, 2: 1-5.

Nourin, N Anjum, S Islam, H Panthi, I Muzammil and SR Panthee, 2019. Overview of trauma cases in CMCH. JCMCTA, Supplement, pp. 53-58.

Paul K, D Vincent, AS George, K Kalyaniwala, A Prajapathi and SM Thomas, 2018. Pattern and outcome of unintentional pediatric trauma in the emergency department of a tertiary care hospital in South India. J. Med. Sci., 38: 269-274.

Rahman R, MA Faiz, S Selim, B Rahman, A Basher, A Jones, C d'Este, M Hossain, Z Islam, H Ahmed and AH Milton, 2010. Annual incidence of snake bite in rural Bangladesh. PLoS Negl. Trop. Dis., 4: 1-6.

Sharma M, BK Lahoti, G Khandelwal, RK Mathur, SS Sharma and A Laddha, 2011. Epidemiological trends of pediatric trauma: A single-center study of 791 patients. J. Indian Assoc. Pediatr. Surg., 16: 88-92.

Sharma S, A Nayak, R Gupta and APS Gaharwar, 2016. Pattern of pediatric trauma in rural background of Central India. IJSS Journal of Surgery, 2: 30-35.

WHO, 2008. World report on child injury prevention. Available at: https://apps.who.int/iris/bitstream/handle/10665/43851/9789241563574_eng.pdf;jsessionid=29F5ABEB8382 3674F58136320FECD821?sequence=1, Accessed: 17 September 2020.

WHO, 2018a. Animal bites: WHO fact sheets. Available at: https://www.who.int/en/news-room/factsheets/detail/animal-bites, Accessed: 17 September 2020.

WHO, 2018b. Falls: WHO fact sheet. Available at: https://www.who.int/en/news-room/fact-sheets/detail/falls, Accessed: 17 September 2020. 